\title{
Conversación en Madrid con Alberto de la Hera*
}

Javier FERRER ORTIZ

Universidad de Zaragoza

Departamento de Derecho Público

Catedrático de Derecho Canónico y Derecho Eclesiástico del Estado

jferrer@unizar.es

Cuando recibí la invitación del profesor Santiago Casas para realizar esta entrevista al profesor Alberto de la Hera, me sentí muy honrado y acepté de inmediato. Nuestra amistad empezó a fraguarse en el II Congreso Internacional de Derecho Eclesiástico Español, que se celebró en Segovia, del 6 al 11 de noviembre de 1986, al que me invitó a participar con una ponencia ${ }^{1}$. El Congreso, luego lo supe, fue ideado por Pedro Lombardía y llevado a la práctica por el propio Alberto, que ante la enfermedad del querido maestro, asumió la Presidencia y su organización. La peculiaridad consistió en que las ponencias fueron distribuidas entre especialistas con una amplia y dilatada trayectoria (Hervada, Bertolino, Ferrari y

* Alberto de la Hera Pérez-Cuesta nació en Granada, el 18 de septiembre de 1932. Es Doctor en Derecho Canónico por la Pontificia Universidad de Santo Tomás de Aquino (Roma), en Filosofía y Letras por la Universidad Complutense de Madrid y en Derecho por la Universidad de Navarra. Fue Profesor Ayudante de Historia de América en la Universidad de Barcelona (1955-1957) y de Historia del Derecho Indiano en la Universidad Complutense (1957-1959), Profesor de Historia del Derecho Canónico en la Universidad de Navarra (1959-1966), catedrático de Derecho Canónico en la Universidad de Murcia (1966-1967) y en la Universidad de Sevilla (1967-1971), catedrático de Historia de América en la Universidad Complutense (1971-2002) y Profesor Emérito de esta Universidad (2002-2006).

Ha sido Decano de la Facultad de Geografía e Historia, Vicerrector y Secretario General de la Universidad Complutense. Entre sus cargos científicos cabe señalar, entre otros, que fue Presidente del Instituto Internacional de Historia del Derecho Indiano, del European Consortium for Church and State Research y de la Asociación Española de Americanistas; y Vicepresidente de la Consociatio Internationalis Iuris Canonici Promovendo. Sigue siendo Vicepresidente de la International Religious Liberty Association y Consultor del Consejo Pontificio para la Interpretación de los Textos Legislativos. También ha sido Director General de Teatro y Espectáculos del Ministerio de Cultura (1979-1980) y Director General de Asuntos Religiosos del Ministerio de Justicia (1966-2004).

1 Cfr. Javier FERrer OrTIZ, Laicidad del Estado y cooperación con las confesiones, en Anuario de Derecho Eclesiástico del Estado, III (1987), pp. 237-248. 
Casuscelli) y una docena de jóvenes doctores españoles, recién incorporados a la Universidad en calidad de Profesores Ayudantes².

A partir de entonces he mantenido un trato ininterrumpido con Alberto, en su calidad de Director del Anuario de Derecho Eclesiástico del Estado del que soy colaborador habitual y encargado de una sección fija, por invitación de Pedro Lombardía, desde su primer volumen de 1985.

Así que con la ilusión de visitar a un querido y admirado maestro y amigo, me encaminé una mañana del mes de abril en el tren de alta velocidad que cubre la distancia de Zaragoza a Madrid; y, en poco más de dos horas, metro incluido, llegué a la casa de Alberto, situada en Moncloa, junto a la Universidad Complutense. Después de los saludos de rigor iniciamos la siguiente conversación.

Pregunta. Podíamos empezar por los datos biográficos, sobre el nacimiento, la infancia...

Respuesta. Mi padre era un sevillano, de Guadalcanal, que fue a estudiar Farmacia a Granada, porque entonces en España solo había cuatro Facultades de Farmacia: Madrid, Barcelona, Santiago de Compostela y Granada. Era bastante frecuente que los farmacéuticos andaluces se casaran con granadinas, porque iban a estudiar la carrera a Granada y se echaban novia allí, que es lo que hizo mi padre. Se casaron en Granada, pero se fueron inmediatamente a Guadalcanal, donde mi padre, recién terminada la carrera, abrió una farmacia y allí se instalaron. Cuando mi madre quedó embarazada -yo soy el primer hijo-, prefirió tenerme en Granada. Entonces no se nacía en clínicas, se nacía en la casa y ella quiso que yo naciera en la misma casa, en la casa de mis abuelos, donde había nacido ella. Poco antes de mi nacimiento mis padres fueron a Granada y allí nací, pero inmediatamente después regresamos a Guadalcanal: de manera que soy granadino de intención de mi madre y de carnet de identidad, pero no he vivido en Granada. Así que mi infancia transcurre entera en Guadalcanal, un pueblo de la Sierra Morena, de la provincia de Sevilla, lindando con Badajoz.

P. ¿Y los primeros estudios, dónde los realizaste?

R. Los estudios infantiles, previos al Bachillerato, los hice en un Colegio de monjas, de la Congregación de la Doctrina Cristiana, que había en Guadalcanal;

2 En concreto, María José Villa (†), Javier Martínez-Torrón, Gloria Morán, Agustín Motilla, Elena Olmos, Ana Fernández Coronado, Ignacio Zabalza, María José Ciáurriz, Gregorina Fuentes, María Elena Buqueras e Isabel Aldanondo. Todos ellos acabamos haciendo carrera universitaria. 
donde por cierto tuve mucha suerte, porque había una hermana, la hermana San Antonio, que era un genio de la docencia, y no es sólo porque me enseñara a leer y a escribir y las cosas más elementales, sino porque educaba muy bien y trataba a sus alumnos proporcionándoles un temprano sentido de la responsabilidad, del trabajo y del sentido de la vida. Y a continuación vino la guerra. Pasé en Granada los primeros meses de la misma, porque habíamos ido a ver a mis abuelos ese mes de julio del 36, a pasar unos días de veraneo en su casa, y nos tuvimos que quedar allí obligatoriamente hasta noviembre o diciembre, cuando conseguimos por fin regresar a Guadalcanal, donde se había quedado mi padre.

Conservo muy malos recuerdos de la guerra en Granada, aunque no tenía más que tres años. Pero a un niño no se le olvidan los bombardeos, ni que le digan que las bombas matan a la gente. Se oía la sirena. Bajábamos, corre que te corre, a un sótano que había en la casa. Mi abuela rezaba. Mi madre me abrazaba y lloraba. Se oían los estallidos de las bombas. Fue horrible. Yo acostaba a mi hermana, un año menor que yo, y le decía: «iTápate, hija mía, no te vaya a caé una gomba!».

Y bueno, por fin fue posible el traslado a Guadalcanal. Durante meses no pudimos saber si mi padre vivía o no, porque allí habían asesinado a mucha gente al empezar la guerra. Y no sabíamos de él porque desde Granada no pudimos comunicarnos de ninguna manera hasta que, avanzado el verano, supimos de él y que le debía la vida a ser farmacéutico. $Y$ es que se salvaron cuatro personas concretas: el médico, el farmacéutico, el practicante y el veterinario, porque a ellos los necesitaban. Cuando por fin pudimos llegar al pueblo ya habían entrado en él las fuerzas llamadas nacionales.

Seguí viviendo allí hasta los ocho años. A esa edad tenía que irme a estudiar a Sevilla, pero como ya tenía tres hermanos más, y a mi padre no le gustaba quedarse en el pueblo y mandarnos internos a un colegio de Sevilla, decidió vender la farmacia de Guadalcanal y abrir una en Sevilla. Y allí nos fuimos toda la familia en el año 40 para que los cuatro hijos pudiéramos estudiar. Estudié el Bachillerato en el Colegio de los Jesuitas, en Sevilla, desde los ocho años hasta que acabé con dieciséis. Entonces el Bachillerato constaba de un curso de ingreso y de siete años más.

P. ¿De esa etapa tienes algún recuerdo que te marcara?

R. Tengo un recuerdo maravilloso del Colegio de los Jesuitas, llamado de Villasís, porque originariamente estaba en la plaza de ese nombre. Ya no existe, pues después de acabar yo el Bachillerato los jesuitas se trasladaron a las afueras de Sevilla, a un colegio nuevo moderno, y el mío desapareció. Era un colegio excelente, donde la educación académica, religiosa, humana y cultural resultaban 
excepcionalmente buenas. Del Colegio de los Jesuitas de Sevilla conservo unos recuerdos preciosos. ¿Anécdotas?

P. Sí, por ejemplo, ¿eras un alumno disciplinado?

R. A eso vamos. Es que en el colegio entonces era bastante frecuente que los mejores alumnos -perdona por atribuirme el calificativo-, los que sacaban sobresalientes en todas las asignaturas, y yo los sacaba porque Dios me dotó de una magnífica memoria y de la astucia suficiente para disfrazar la memoria de inteligencia, digamos que los dos o tres primeros alumnos de cada curso, resultaban de hecho casi intocables... Recuerdo perfectamente que uno de los padres jesuitas, inspector nuestro, un hombre de bien donde los haya, nos decía con una gran sonrisa: «iEn este colegio hay demasiados rectores!» Y se estaba refiriendo a los dos o tres que nos aprovechábamos de la situación para saltarnos con frecuencia la disciplina, sin que ello nos trajera consecuencias. Si hasta la normativa del colegio decía que, en casos de castigos colectivos, los alumnos de cierto nivel no estaban obligados a cumplirlos...

P. Cuando terminaste la etapa escolar ¿ya sabías qué carrera querías estudiar?

R. A mí me en el colegio me encantaban las Letras y me aburrían las Ciencias. A mi padre le hubiera gustado mucho que fuese farmacéutico para sucederle en la farmacia. Era su ilusión. Pero a mí la Física, la Química, las Ciencias Naturales, la Biología..., todo lo que era Ciencias no me interesaba lo más mínimo. Sacaba buenas notas por lo que he dicho antes, porque tenía buena memoria... Si me preguntas la definición de derivada, te digo que es «el límite al que tiende el incremento de una función cuando la variable tiende a cero», pero no sé lo que significa. De eso no sé nada. En cambio, me encantaban las Letras: la Historia, la Literatura, la Filosofía, el Arte..., eso me encantaba.

Cuando terminé el Bachillerato, a los dieciséis años, mi padre esperaba que hiciera Farmacia y le dije que yo prefería estudiar Filosofía y Letras. Entonces no había, como ahora, Facultades de Geografía e Historia, Literatura, Filosofía, Psicología, etc., sino que se trataba de una única carrera. Así que le dije a mi padre que lo que me gustaba eran las Letras, sobre todo la Historia, y que a eso quería dedicarme. Mi padre me contestó que con eso no se gana dinero y que si quería estudiar Letras que estudiara Derecho. Entonces me matriculé en Derecho, por darle gusto a él, pero le pedí permiso para matricularme a la vez en Filosofía y Letras. Me dijo que si me creía capaz que lo hiciera, y me matriculé en las dos Facultades.

P. ¿De la carrera de Derecho qué recuerdos tienes?

R. Empecé los estudios en la Universidad de Sevilla sin excesivo entusiasmo, pero en el segundo curso tuve un maestro, don Manuel Giménez Fernán- 
dez ${ }^{3}$, catedrático de Derecho Canónico, que había sido ministro de Agricultura con la Segunda República en los Gobiernos demócrata-cristianos y que pertenecía al partido de Gil Robles. Era un profesor absolutamente excepcional: buenísimo, deslumbrante. Y a mí me cautivó el Derecho Canónico y su manera de explicarlo.

P. ¿Qué Derecho Canónico se estudiaba entonces?, ¿¿la Parte General, el Derecho matrimonial, el Derecho procesal...?

R. No, no, se estudiaba lo que quería don Manuel Giménez Fernández. Él compatibilizaba el Derecho con su gran afición a la Historia de América. Tiene un libro magnífico sobre Bartolomé de las Casas. Y lo que explicaba fundamentalmente era la Historia de las Relaciones entre la Iglesia y el Estado. Lo hacía maravillosamente. Era interesantísimo. Te hacía seguir la historia al pie de la letra, con una enorme cantidad de detalles, y a la vez con interpretaciones muy interesantes. En su manos era una asignatura deslumbrante. Y entonces yo me enamoré del Derecho Canónico que explicaba Giménez Fernández. Y andando el tiempo, como veremos más adelante, me especialicé en esa materia. Por eso, por encima de todo me considero un historiador de las Relaciones entre la Iglesia y el Estado, concretadas en América, que era justamente lo que enseñaba Giménez Fernández. Estamos hablando de finales de los años 49-50, cuando le quedaban 20 años para jubilarse.

Recuerdo que él era muy amigo de un tío mío, que se llamaba Felipe de la Hera, y se le metió en la cabeza que mi nombre era Felipe, y me llamaba siempre así. Y no fue el único caso en que prevalecía sobre mi nombre el nombre de mis mayores. Otro ejemplo: el catedrático de Historia del Derecho Indiano de la Facultad de Filosofía y Letras de Sevilla, Antonio Muro Orejón, que había sido compañero de Bachillerato de mi padre, también me llamaba siempre con el nombre completo de mi padre, Alberto de la Hera Rivero. Puedes comprobarlo en los libros de este profesor sobre Historia del Derecho Indiano: siempre que

3 Cfr. Alberto DE la HerA, «In memoriam». Prof. D. Manuel Giménez Fernández (†), en Ius Canonicum, 9 (1969), pp. 495-498, donde ofrece una semblanza de su primer maestro y una relación de su producción científica, centrada en los trabajos canonísticos y americanistas. Vid. también José Calvo González y Manuel J. PeláeZ, «Giménez Fernández, Manuel (1896-1968)», en Manuel J. PELÁEZ (dir., ed. y coord.), Diccionario de Canonistas y Eclesiasticistas europeos y americanos (II). Semblanzas del año 1000 al 2018, Saarbrücken, 2018, pp. 230-234; y Carlos PETIT, «Giménez Fernández, Manuel (1896-1968)», en Diccionario de Catedráticos Españoles de Derecho, http://portal.uc3m.es/portal/page/portal/instituto_figuerola/programas/phu/diccionariodecatedraticos/ lcatedraticos/gifernandez [fecha de consulta 6-V-2019]. 
me cita en sus notas, una vez que yo también accedí a la cátedra, me cita con el nombre y los dos apellidos de mi padre.

Y puedo seguir dando ejemplos. Muchos años después, en 1979, cuando me designaron Director General del Teatro del Ministerio de Cultura, el ministro que lo hizo, Manuel Clavero Arévalo, sevillano, le facilitó a su secretaria los nombres de varios nombramientos para publicarlos en el Boletín Oficial del Estado, y ésta le hizo notar que faltaba mi segundo apellido, a lo que contestó: «No lo sé, pero puede comprobarlo en la guía de teléfonos de Sevilla». Pero allí figuraba mi padre, no yo. Así que en el Boletín Oficial salió nombrado Director General de Teatro mi padre, un farmacéutico de setenta y tantos años. Al día siguiente hubo que rectificarlo, pero mientras tanto puede imaginarse la sorpresa causada en Sevilla, con todos los amigos y colegas de mi padre llamándole estupefactos ante aquel nombramiento. Así que ya se ve que mi personalidad ha estado siempre sumergida bajo la de mis mayores.

P. Volviendo a la carrera de Derecho...

R. Cuando terminé segundo curso fui a hablar con Giménez Fernández y le dije que quería ser catedrático, porque me había pasado el Bachillerato soñando con ser profesor del colegio y ahora ya soñaba con ser profesor de la Universidad. $\mathrm{Y}$, en concreto, le dije que quería ser catedrático de Derecho Canónico, porque me habían entusiasmado sus explicaciones sobre las Relaciones Iglesia-Estado. Y me contestó: «Para ser catedrático de Derecho Canónico hoy es muy conveniente tener un doctorado eclesiástico; en estos momentos en España la asignatura está casi exclusivamente en manos de sacerdotes, y ellos aprecian mucho los doctorados en Facultades de la Iglesia». Así que cuando terminé tercero de Derecho, pedí una beca al Consejo Superior de Investigaciones Científicas para ir a Roma y obtener un doctorado en Derecho Canónico en un centro pontificio. Tenía muy buen expediente -no es por presumir-y me la dieron, y con ella me fui a Roma, donde me matriculé en el Pontificio Instituto Internacional Angelicum, hoy Pontificia Universidad de Santo Tomás de Aquino. Y allí estuve tres años. En junio del primer año me examiné de las asignaturas del Bachillerato en Derecho Canónico pontificio, en el segundo año de la Licenciatura, y en el tercer año del Doctorado. Leí la tesis doctoral con veintidós años en Roma. Y, durante todo ese tiempo, pasaba los veranos en España, estudiando para examinarme en septiembre como alumno libre de las asignaturas de Derecho y Filosofía y Letras, con el fin de no perder cursos.

P. ¿Seguías matriculado en la Universidad de Sevilla?

R. No. El cuarto curso de Derecho lo hice en Madrid y el quinto en Granada. Giménez Fernández me aseguró que no sólo debía obtenerse el doctorado 
en Roma, sino que convenía acercarse a don Eloy Montero, que era el catedrático de Derecho Canónico de la Universidad de Madrid, hoy Complutense, en cuanto que estaba entonces considerado como la primera autoridad científica y universitaria en nuestro campo en España ${ }^{4}$. Por otra parte, a mí me interesaba tanto como el Derecho Canónico la parte americanista de las Relaciones IglesiaEstado, y en eso -me informó también Giménez Fernández-, el gran maestro era don Alfonso García-Gallo ${ }^{5}$, que también estaba en la Universidad de Madrid. Por eso hice allí cuarto de Derecho y de Filosofía y Letras. Y deseando que quedara alguna relación entre mi vida universitaria y mi ciudad natal, hice por libre el quinto curso de Derecho en Granada. Estudiar por libre suponía entonces no tener obligación de ir a clase, y así a Granada acudí solamente para los exámenes, pero ello le permitió a un granadino tener una licenciatura universitaria por Granada. En cambio, quinto de Filosofía y Letras lo hice en la Universidad de Madrid.

P. ¿Y del Angelicum qué recuerdos conservas?

R. El Derecho Canónico que entonces se explicaba en las Universidades de la Iglesia respondía al carácter exegético señalado en las normas que se publicaron a raíz de la entrada en vigor del Codex de 1917. Una enseñanza puramente exegética, canon tras canon, una exposición práctica sin mayores bases científicas. En los exámenes te preguntaban un canon y tenías que decirlo prácticamente de memoria. Estudiábamos el Código y los apuntes de clase, sin mayor profundidad. No tenía gran valor científico.

Sin embargo, recuerdo que tenía un catedrático de Filosofía del Derecho, el P. Bender, un holandés que era muy exigente y muy poco accesible, pero que planteaba sus enseñanzas con altura científica. El Decano de la Facultad era el P. Severino Álvarez Menéndez, un asturiano, sumamente amable, que tenía un bufete canonístico para casos ante el Tribunal de la Rota, y ese era el terreno en que

4 Cfr. Manuel J. PELÁEZ, «Montero Gutiérrez, Eloy (1887-1972)», en Manuel J. PELÁEZ (dir., ed. y coord.), Diccionario de Canonistas y Eclesiasticistas europeos y americanos (II). 1369 semblanzas del año 1000 al 2015, Saarbrücken, 2012, pp. 324-326; y José María PUYOL MONTERO, «Montero Gutiérrez, Eloy (1887-1972)», en Diccionario de Catedráticos Españoles de Derecho, http://portal. uc3m.es/portal/page/portal/instituto_figuerola/programas/phu/diccionariodecatedraticos/lcatedraticos/ mgutierrez [fecha de consulta 6-V-2019].

5 Cfr. José Antonio EsCUdERO, «Alfonso García-Gallo (1911-1992)», en Rafael Domingo (ed.), Furistas Universales, vol. IV, Madrid-Barcelona, 2004, pp. 600-606; y Braulio DíAZ SAMPEDRO, «García-Gallo de Diego, Alfonso (1911-1992)», en Diccionario de Catedráticos Españoles de Derecho, http://portal.uc3m.es/portal/page/portal/instituto_figuerola/programas/phu/diccionariodecatedraticos/lcatedraticos/garciagallodediego_a [fecha de consulta 6-V-2019]. 
se movía. Y el profesor de Historia del Derecho Canónico, que era lo que a mí más me interesaba, era un italiano, el P. Emmanuele Canzoneri. Le propuse hacer mi tesis sobre «Los orígenes del Derecho Canónico indiano», un tema del que él lógicamente no tenía el menor conocimiento. Aceptó dirigirme la tesis, pero ya me advirtió de que no podría ayudarme a hacerla, solamente analizarla una vez hecha para valorarla o corregirla. No me salió del todo mal, porque cuando la terminé se la envié al profesor García-Gallo, y me la publicó en el Anuario de Historia del Derecho Español ${ }^{6}$, que es una revista de gran prestigio. La bibliografía y las fuentes las encontré en la Biblioteca Apostólica Vaticana y en el Archivo Secreto Vaticano, a donde iba todos los días, logrando compaginar el tiempo de investigación con el curso de doctorado en el Angelicum. Y allí hube de realizar en latín la exposición y defensa de la tesis ante el correspondiente tribunal; en latín eran también las clases y los exámenes. Por fortuna, en mi Bachillerato hube de estudiar a fondo el latín durante siete años, y llegué a dominarlo bastante bien. Con el tiempo, incluso he tenido que dar alguna conferencia en latín, recuerdo una en la Pontificia Universidad Gregoriana, en Roma, y alguna que otra más.

P. ¿Volviendo hacia atrás, podemos situar los años de tus estudios universitarios?

R. En la Universidad de Sevilla hice primero el curso 49-50, segundo el curso 50-51 y tercero el curso 51-52, tanto de Derecho como de Filosofía y Letras. En octubre de 1952 me fui a Roma y, como he explicado antes, seguí estudiando esas carreras durante los veranos y examinándome en septiembre como alumno libre. Terminé Derecho en Granada, y Filosofía y Letras en Madrid. Así que cuando volví de Roma en 1955 era Doctor en Derecho Canónico, y Licenciado en Derecho y en Filosofía y Letras.

P. ¿Llegaste a conectar con profesores de la Facultad de Filosofía y Letras?

R. Conecté fundamentalmente con don Alfonso García-Gallo. En Roma había un Instituto Jurídico Español que dirigía el profesor Rafael Gibert y Sánchez de la Vega, catedrático de Historia del Derecho y discípulo de García-Gallo. En ese Instituto solo había tres becarios: uno era un civilista de Valladolid, otro un procesalista de Madrid y el otro yo. Nos visitaban periódicamente profesores de las distintas asignaturas, incluido García-Gallo, que iba con cierta frecuencia, una vez cada dos meses, aproximadamente. Así que puedo decir que, de facto, fue el director de la tesis doctoral que yo estaba haciendo en Roma, sobre los precedentes americanos del Derecho canónico indiano.

6 Cfr. Alberto DE LA HERA, El derecho de los indios a la libertad y a la fe. La bula «Sublimis Deus» y los problemas indianos que la motivaron, en Anuario de Historia del Derecho Español, 1956, pp. 89181. Este es el título del extenso artículo en el que se convirtió la tesis doctoral. 
Cuando regresé a Madrid en 1955, lo primero que hice fue ponerme en contacto con el profesor García-Gallo, para continuar trabajando bajo su magisterio. Él era catedrático de Historia del Derecho en la Facultad de Derecho y encargado de la cátedra de Derecho indiano en la Facultad de Filosofía y Letras, rama de Historia de América. En esas estaba yo, tratando de encontrar mi lugar en Filosofía y Letras, cuando un joven profesor de Historia de América, Jaime Delgado Martín, obtuvo la cátedra de Historia General de América en la Universidad de Barcelona. Como allí no había nadie más, pues entonces éramos muy pocos los que nos dedicábamos a la Historia de América, me propuso que le acompañara como Ayudante, y allí me fui a mis veintitrés años.

Recuerdo que para poder tomar posesión de la plaza de Ayudante de cátedra tenía que prestar juramento de fidelidad a los Principios del Movimiento Nacional. Estábamos en pleno Régimen de Franco. Me dirigí al organismo pertinente y me sucedió la siguiente anécdota. El funcionario que me atendió, en lugar de pedirme juramento, va y me pregunta: «¿Usted en el año 36 qué hacía?» Y le dije: $\ll_{i}$ Tomar el biberón!». Y eso fue suficiente.

Corría el mes de octubre, empezó el curso, acudía a las clases de Jaime Delgado, estudiaba bajo su dirección, le sustituía en clase cuando era necesario, y en general formábamos un pequeño equipo responsable de la asignatura en aquella Universidad. En el segundo trimestre tuvo él que ausentarse a Madrid con alguna frecuencia, y por ello hube de dar un número relativamente alto de clases siguiendo el programa que me señalaba.

P. ¿Te acuerdas qué temas te tocó explicar?

R. No, pues no eran temas completos, sino la parte de varios de ellos que el profesor Delgado me iba señalando. Fue una buena experiencia dar bastantes clases y tocar puntos muy diversos del programa. Teníamos solamente una docena de alumnos, ya que salvo en Sevilla, dada la presencia del Archivo de Indias, nuestra asignatura la cursaban pocos estudiantes. Yo seguía el programa y los libros que el profesor Delgado me indicaba, temas de Historia General de América General, no de Derecho indiano ni de Relaciones Iglesia-Estado, y así empecé a dar clase y entré con mayor profundidad en el conjunto de la asignatura.

P. ¿Cuál fue tu experiencia en la Universidad de Barcelona y basta cuándo duró?

R. En Barcelona estuve dos años como Ayudante, los cursos 55-56 y 56-57. Y en 1957 acabé esa etapa de mi vida, cuando García-Gallo me ofreció ser Ayudante suyo en la Facultad de Derecho, en su cátedra de Historia del Derecho, y trabajar con él también en la Facultad de Filosofía y Letras, en la cátedra de Derecho indiano. Y regresé a Madrid como Ayudante de cátedra, esta vez ya con sueldo, 792 pesetas mensuales, que entonces no sé cómo me daban para vivir. En 
Barcelona no había tenido sueldo, pero me mantuve mediante becas, sistema muy habitual entonces -al menos lo fue para mí- y del que viví durante bastantes años antes de consolidarme en puestos ya rentables de trabajo.

P. ¿Cómo transcurrió tu etapa como Ayudante en la Universidad de Madrid?

R. Como he dicho antes, García-Gallo era catedrático en la Facultad de Derecho y encargado de cátedra en la de Filosofía y Letras, así que repartía su docencia entre las dos. En los cursos que trabajé con él, 57-58 y 58-59, no me correspondió dar clases; García-Gallo era en ese punto muy personal y muy activo, y ya que entonces no existían las llamadas clases prácticas, la labor de los Ayudantes era de una lado administrativa, y de vigilancia de exámenes, y sobre todo de largas conversaciones con el maestro en torno a los temas que bajo su dirección estudiábamos los que trabajábamos con él. Unas conversaciones en las que seguía paso a paso nuestros estudios, estaba sobre ellos, los orientaba, nos conducía hacia la conclusión de trabajos que fuesen publicables, y que desde luego también se ocupaba de publicar. Un verdadero maestro.

P. ¿Y en ese tiempo qué más hiciste?

R. En esos dos años preparé la tesis doctoral en Filosofía y Letras, sobre «El regalismo borbónico en su proyección indiana». El tema me lo proporcionó Ismael Sánchez Bella, catedrático de Historia del Derecho en la Universidad de Navarra y discípulo de García-Gallo. Al maestro le pareció muy bien, y del año 57 al 59 hice la tesis. Los documentos los obtuve del Archivo de Indias, en Sevilla, adonde viajaba regularmente desde Madrid. En cada estancia sacaba unas doscientas fichas, me volvía y seguía trabajando en Madrid. Al mes siguiente repetía la operación. Todavía conservo los ficheros; entonces se trabajaba todo a mano, la informática no había hecho aún su aparición.

A base de los datos del Archivo, y de la bibliografía que García-Gallo me proporcionaba, concluí mi segunda tesis doctoral. La defendí en 1959, y la publiqué como monografía ${ }^{7}$. El tribunal que la juzgó estaba presidido por don Ciriaco Pérez Bustamante, eran sus vocales don Cayetano Alcázar Molina, don Manuel Ballesteros Gaibrois y don Alfonso García-Gallo, y ocupaba la Secretaria don Florentino Pérez-Embid, todos ellos catedráticos en la Facultad de Filosofía y Letras de la Universidad Complutense: los dos primeros eran catedráticos de Historia General de América, don Manuel era catedrático de Historia Prehispánica y don Florentino de Historia de los Descubrimientos Geográficos y Geografía de América. La tesis es hoy un libro que se ha transformado en un clásico en la Historia de la Iglesia en

7 Alberto DE LA HERA, El regalismo borbónico en su proyección indiana, Madrid, 1963. 
América, y que ha sido citado hasta la saciedad. No quiero decir que el mérito sea mío que lo redacté, es sobre todo de García-Gallo que me lo dirigió.

P. ¿Y después de este segundo doctorado en 1959 qué pasó?

R. En aquel momento tenía el propósito de continuar trabajando con mi maestro, García-Gallo, para optar la cátedra en su debido momento. Un momento no tan inmediato, porque realmente cátedras de Historia de América había muy pocas en toda España. Pero entonces apareció en escena Pedro Lombardía ${ }^{8}$. Ya le conocía, pero no había tenido mayor trato con él. Cuando llegué a Roma, él ya había regresado a España -había cursado también Derecho Canónico en el Angelicum- para encargarse de la cátedra de Derecho Canónico en la recién creada Universidad de Navarra. Desde allí opositó y obtuvo cátedra en la Universidad de Zaragoza, que ocupó durante un curso, mientras que en Pamplona le sustituía su primer discípulo, Javier Hervada; éste durante ese curso preparó a su vez la oposición a cátedra, y cuando, al cabo de solo un curso, Lombardía regresó a Pamplona, Hervada obtuvo la cátedra de Zaragoza.

En 1959 se erige en la Universidad de Navarra el Instituto de Derecho Canónico 9 , germen de la futura Facultad del mismo nombre. Pedro Lombardía asumió la tarea de formar el claustro con media docena de profesores. Y me llamó para que me encargara de la cátedra la Historia del Derecho Canónico. Hablé con García-Gallo y le pareció bien, teniendo en cuenta que ya había defendido la tesis y que me interesaba no sólo el Derecho indiano en general sino en especial el Derecho Canónico indiano. Entonces pasé a Pamplona, donde estuve trabajando, bajo la dirección de Pedro Lombardía y de don José Orlandis, catedrático

8 Cfr. Alberto DE LA HeRA, Pedro Lombardía e il rinnovamento del diritto canonico spagnolo, en Quaderni di diritto e politica ecclesiastica, 1986, pp. 207-223; ID., Pedro Lombardía (1930-1986): Notas para su biografía cientifica, en AA.VV., Las relaciones entre la Iglesia y el Estado. Estudios en memoria del profesor Pedro Lombardía, Madrid, 1989, pp. 33-45 (versión española del artículo anterior); y, más recientemente, ID. El magisterio de Pedro Lombardía (1930-1986) en su trigésimo aniversario (2016), en Anuario de Derecho Eclesiástico del Estado, XXXIII (2017), pp. 105-128. Vid. también Javier HERVADA y Juan ForNÉS, «Pedro Lombardía 1930-1986)», en Rafael DOMINGO (ed.), Furistas Universales, vol. IV, cit., pp. 722-726; y Juan FoRNÉS, «Lombardía, Pedro», en Javier OTADUY, Antonio Viana y Joaquín SEDANO (dirs. y coords.), Diccionario General de Derecho Canónico, vol. V, Pamplona, 2012, pp. 213-216.

9 Cfr. José OrLandis, El Instituto de Derecho Canónico de la Universidad de Navarra, en Ius Canonicum, 50 (100), pp. 385-397. El que fuera su primer director relata las circunstancias que rodearon la puesta en marcha del Instituto y deja constancia, casi al final de su relato, que su primer Senatus o Junta Directiva estaba compuesta, entre otros, por Alberto de la Hera, en calidad de Bibliotecario (ibid., p. 396). 
de Historia del Derecho, con Javier Hervada, Víctor Reina, Pedro-Juan Viladrich, Bill Stetson, Cecilio Lázaro, etc.

En 1961 fundamos la revista Ius Canonicum. Pedro me llamó para que le asesorara y entre los dos la organizamos, nombre incluido. La idea la tuvimos en 1960, pero nos pareció que sería mucho mejor que el primer número fuera del 61, el segundo del 62 y así sucesivamente. Hay un artículo muy posterior, en el que se recuerdan sus orígenes y se dice, no son palabras textuales: Pedro Lombardía se encargó de la dirección pero, no teniendo las cualidades administrativas y de oficina que sí tenía Alberto de la Hera, le encargó la secretaría ${ }^{10}$. Así que fui el primer secretario de Ius Canonicum. Él no era ciertamente un administrativo ni un oficinista -para eso ya servía yo de modo suficiente- pero era un director verdaderamente de bandera.

P. ¿Hasta cuándo estuviste en Pamplona?

R. En la Facultad de Derecho Canónico me encargué de Historia del Derecho Canónico durante tres cursos: 59-60, 60-61 y 61-62, poniendo especial énfasis en las Relaciones entre la Iglesia y el Estado. En aquel momento no pensaba salir de Pamplona en mi vida. Estaba muy contento allí; no había realmente opositado a cátedra, pero la Universidad de Navarra era una maravilla en todos los sentidos, y la Escuela de canonistas de Pedro Lombardía había alcanzado en poco tiempo un muy alto prestigio nacional e internacional; nos visitaban las primeras figuras en nuestro campo, nos llamaban a conferencias y congresos, teníamos todo lo deseable.

$\mathrm{Y}$ entonces mis padres hicieron un viaje a Pamplona para visitarme y ver también a Antonio Fontán, entonces Decano de la Facultad de Filosofía y Letras,

10 Cfr. Eduardo J. Guerrero PÉREZ, Los protagonistas de la revista Ivs Canonicom, en Excerpta e Dissertationibus in Iure Canonico. Cuadernos Doctorales de la Facultad de Derecho Canónico, 24 (20102011), pp. 305-405. El texto original dice así: «Entre las muchas cualidades de Pedro Lombardía no estaban las características del hombre práctico, habilidoso y eficaz en la resolución de los aspectos más materiales y ejecutivos. Algunas de esas cualidades eran necesarias, imprescindibles para resolver muchas de las cuestiones que necesariamente se planteaban al director de la revista y más aún en sus primeros momentos. Pero contó entonces con la colaboración de un Secretario especialmente bien dotado para resolver aquellas carencias del Director: Alberto de la Hera (1961-67)» (ibid., p. 341). Más adelante, el autor, abunda en la misma idea, al afirmar: «Fue sin duda un gran apoyo para Pedro Lombardía en los años primeros ya que De la Hera poseía la capacidad organizadora y el sentido práctico de que carecía aquel. Es muy posible que, entre otros, A. de la Hera haya tenido mucho que ver con los aspectos de la presentación gráfica de la Revista, así como el marcado interés por abordar temas históricos o resaltar el marco histórico del Derecho de la Iglesia y la especial atención a las cuestiones Iglesia-Estado -y más en concreto al Derecho Concordatario-, al que se había dedicado preferentemente. Sin hacer referencia a sus muy abundantes reseñas bibliográficas es un asiduo colaborador de la Revista, especialmente en sus primeros años, donde aparecen dieciocho artículos y notas» (ibid., p. 357). 
pariente nuestro y natural de Guadalcanal -de hecho, años más tarde, el rey Juan Carlos I le nombró Marqués de Guadalcanal, y él y yo somos las únicas personas que hemos recibido la Medalla de Oro de aquel Ayuntamiento-. Sin decirme nada mis padres fueron a hablar con él y le dijeron: «Nos da mucha pena que Alberto esté en Pamplona, año tras año, y que no saque cátedra de Universidad. Que sea catedrático y que luego haga lo que quiera». Antonio habló con Pedro Lombardía y como resultado éste vino a verme y me aconsejó que preparara la oposición a cátedra. Para tal fin me propuso que fuese a Alemania y estudiase allí durante un curso Derecho Canónico e Historia del Derecho. Entonces el estudiar en Alemania te daba un notable prestigio, como hemos visto que años atrás te lo daba el haber estudiado en Roma. Y en el año 62 me fui para allá.

P. ¿Cómo ibas de idiomas? ¿Ya sabías alemán?

R. Entonces no sabía ni una palabra de alemán. No he sabido inglés nunca, sé español, italiano, y en menor medida francés y alemán. No sé inglés porque nunca he vivido en un país de habla inglesa; no he logrado nunca aprender idiomas estudiando, solamente pasando tiempo en los países en que se hablan.

Como te digo, en 1962 no sabía nada de alemán, pero tampoco me preocupaba excesivamente porque iba a estudiar Historia de las Relaciones IglesiaEstado en el siglo XVIII. Ten en cuenta que el libro sobre el Regalismo borbónico, en el que me había especializado, versa sobre ese siglo, y los libros de esa época están escritos en latín. Entonces me fui a la Embajada de Alemania en Madrid y pedí una beca. Les dejé mi curriculum vitae y, al cabo de unos días, volví y me dijeron que me la concedían. También me preguntaron si dominaba el alemán y les dije que en absoluto. Ante su extrañeza les expliqué que toda la bibliografía que me interesaba estaba en latín. No obstante, me dijeron que necesitaría el idioma para manejarme en la calle y para seguir las clases; así que me ofrecieron una beca para que aprendiera alemán y se comprometieron a darme otra para investigar, cuando lo dominara. Me enviaron al Goethe Institut de un pueblo de Baviera, llamado Rothenburg of der Tauber, de unos 500 habitantes, donde nadie hablaba otro idioma que no fuera alemán, incluida la familia donde me alojaron y el propio Goethe Institut. Los alumnos éramos españoles, paraguayos, turcos, venezolanos, suecos, ingleses o chinos, y desde la primera clase a la última, nunca, ni un solo día, nos dijeron una palabra que no fuera en alemán. Al cabo de dos meses más o menos empezábamos a hablar en alemán.

P. ¿A partir de abí cómo transcurrió tu estancia en Alemania?

R. Concluido el aprendizaje de la lengua en Rothenburg, pasé a Bonn, en cuya Universidad estatal me puse a estudiar Historia del Derecho y Derecho Canónico con el profesor Barion, que estaba ya jubilado, pero era una primera 
autoridad científica. Al ver que me interesaba mucho la materia, y que tenía una buena base, me ofreció darme clases particulares en su casa. Cada día pasábamos varias horas de charla, abriéndome horizontes, señalándome bibliografía, corrigiendo mis líneas de investigación...; me aprovechó mucho aquella enseñanza, que compaginé con asistencia a las clases de diversos profesores tanto en Derecho como en Teología, que me resultaron notablemente útiles.

Entre las clases a las que asistí, resulta notable el porqué lo hice a algunas de ellas, concretamente a determinadas clases de Teología. Meses antes se había celebrado la primera sesión del Concilio Vaticano II, la única presidida por el papa Juan XXIII, que falleció poco después. Un buen día me fijé en un anuncio, en los pasillos de la Universidad de Bonn, que anunciaba un ciclo de cuatro conferencias a cargo del profesor Joseph Ratzinger, catedrático de Teología Dogmática, sobre aquella primera sesión del Concilio, a la que había acudido como asistente del cardenal de Colonia, Joseph Frings. El día en que tales conferencias iban a iniciarse, diez minutos antes de las once, hora prevista para el comienzo de la primera, acudí al aula correspondiente, y me encontré con que junto a la puerta de la misma vendían entradas en una mesita. No me extrañó, pues había comprobado que si entre clase y clase le pedías un cigarrillo a un compañero te lo daba pero se lo tenías que pagar, o que si ibas a la casa de un amigo que vivía en un tercer piso subías por la escalera, pero si querías subir en el ascensor pagabas unas monedas para que funcionara. Y así todo: en la residencia universitaria donde vivía había una ducha de agua fría, pero si querías que saliera agua caliente tenías que echar unas monedas. Pues bien, cuando faltaban cinco minutos para el comienzo de la conferencia, la mesita fue retirada y se dejaron de vender entradas al aula; todo el aforo había sido cubierto. Quedábamos quince personas en la cola, catorce alemanes y un español. Los alemanes se volvieron a sus quehaceres y el español, o sea yo, entró en el aula por una ventana, y escuchó la conferencia. Y nadie dijo nada, pues allí, si alguien entraba por una ventana y se quedaba de pie al fondo, se daba por supuesto que era legítimo que esa persona actuase así. Por supuesto, los demás días llegué media hora antes y pagué debidamente mi entrada.

Pues bien, las conferencias de aquel profesor Ratzinger, que había obtenido la cátedra poco antes, fueron realmente deslumbrantes. $\mathrm{Y}$ entonces, por mi cuenta, sin pedirle permiso a nadie, siempre que pude acudí a sus clases, no tanto para aprender Teología sino para aprender a dar clase. La sistemática, la claridad, el orden con que explicaba aquel hombre, sin pizarra, sin papeles, con una metodología perfecta, eran ejemplares. Muchos años después, siendo cardenal, fue nombrado Doctor honoris causa por la Universidad de Navarra. Entonces yo vivía en Madrid y fui a Pamplona expresamente a asistir al acto académico, porque no 
le veía desde entonces, cuando tenía treinta años. Comprobé que era el mismo profesor que había conocido en la Universidad de Bonn, absolutamente deslumbrante y, además, tuve la suerte de saludarle personalmente. Son las dos únicas veces en que he estado con él. Y me honra haber tenido esa posibilidad de conocerle y apreciarle. Otros profesores, a lo largo de mi extensa vida de estudioso, me enseñaron Historia del Derecho indiano, Historia de la Iglesia, Historia de las Relaciones Iglesia-Estado, Derecho Canónico..., pero de Ratzinger aprendí a dar clase.

Volviendo atrás, el tiempo que estuve Alemania lo repartí a partes iguales entre Bonn, donde estudié principalmente Historia del Derecho, y Múnich, donde seguí las clases de Klaus Mörsdorf, el gran canonista alemán de entonces, y fui condiscípulo del luego cardenal Antonio Rouco Varela y también conocí a otros alumnos que luego han sido a su vez grandes profesores, como por ejemplo Aymans, al que en tantos otros momentos de la vida científica he encontrado en diferentes reuniones y congresos. En Múnich, en la Escuela de Mörsdorf, se enseñaba un Derecho Canónico de naturaleza teológica, una nueva perspectiva que amplió de manera notable mi conocimiento de todas las variantes doctrinales del pensamiento canonístico.

P. ¿Y qué biciste cuando regresaste a España?

R. En 1964 volví a Pamplona, donde durante dos cursos me dediqué, bajo la dirección de Pedro Lombardía, a preparar la cátedra de Derecho Canónico. Durante todo el curso 65-66, habiendo ya firmado la oposición convocada para las cátedras de Murcia y La Laguna, asistí a las clases que Pedro Lombardía impartía en la Facultad de Derecho, sentado entre los alumnos, para aprender a dar clase de Derecho Canónico en España. Tras explicar la Parte General, Pedro encomendó las clases de Derecho matrimonial a Víctor Reina. Sus clases, como también las que le escuché más tarde a Pedro-Juan Viladrich, poseían un altísimo nivel de brillantez. Puede decirse que, en este sentido, ambos discípulos aventajaban al maestro, quien por su parte era insuperable en el trato humano directo y en las tareas de dirección de tesis, de trabajos, de estudios...; como maestro era único, no he conocido otro de tanta calidad.

P. ¿Cómo fue la oposición y en qué consistía?

R. Al final la oposición para cubrir las dos cátedras vacantes de las Universidades de Murcia y La Laguna comenzó el 12 de junio de 1966 y concurrimos doce opositores. El sistema, con seis ejercicios, resultaba muy completo y altamente revelador de las cualidades y conocimientos de cada aspirante; se distinguía notablemente del sistema actual. El tribunal lo presidía el obispo de Tuy, Fray José López Ortiz, antiguo catedrático de la Facultad de Derecho de la 
Universidad Complutense; eran sus vocales los profesores Ramón Lamas Lourido, que fuera catedrático en la Universidad de Valencia y luego Prelado Auditor de los Tribunales de la Rota de Roma y de Madrid, Paulino Pedret Casado, catedrático en Santiago de Compostela, y Miguel Hernández Ascó, catedrático en Valladolid; la Secretaría la ocupaba Antonio Mostaza, catedrático en Valencia. Cuatro catedráticos sacerdotes y un solo seglar (Hernández Ascó), personas todos de conocida valía. Obtuvimos plaza José Luis Santos y yo, que elegí Murcia. Entre los opositores estaban Víctor Reina, Luis Portero Sánchez, Mariano López Alarcón, José Ángel Fernández Arruty, todos los cuáles no tardaron en obtener plaza en subsiguientes oposiciones.

Como ya indiqué, la oposición constaba de seis ejercicios: el primero era la exposición del propio curriculum vitae, el segundo la del concepto de la asignatura que cada opositor tuviese, el tercero una lección del programa elegida por el opositor, el cuarto otra lección que elegía el tribunal, el quinto un caso práctico, y el sexto era un ejercicio libre a decidir por el tribunal, que en nuestro caso fueron veinte temas doctrinales y legislativos que el tribunal propuso y de los que por sorteo se elegían dos.

Para el tercer ejercicio, por sugerencia de Pedro Lombardía, me ocupé de La norma singular, trabajo que posteriormente publiqué ${ }^{11}$. Y en el cuarto ejercicio hube de ocuparme de la teoría general del Derecho Canónico según la línea doctrinal que considerase más cercana a mi pensamiento, de modo que me atuve a la exposición y análisis crítico de una serie de enseñanzas de Javier Hervada que yo había podido estudiar con mucho detalle. Luego en el quinto el Tribunal nos propuso un caso práctico matrimonial para resolverlo y un texto del Corpus Iuris Canonici para identificarlo y comentarlo. Y en el sexto los dos temas que por sorteo me correspondieron fueron La persona jurídica y Párroco, parroquia y templo parroquial. $\mathrm{Al}$ término de la oposición obtuve el número uno y ocupé la cátedra de Murcia.

11 Alberto DE la Hera, La norma singular, en Rafael NaVARRO-VAlls, Juan Calvo OTERo y Antonio MARTÍNEZ BLANCo (presentación), Dimensiones jurídicas del factor religioso. Estudios en bomenaje al Profesor López Alarcón, Murcia, 1987, pp. 205-224. Las normas singulares o actos flexibilizadores de las normas con generalidad, constituyen uno de los temas ampliamente discutidos por la doctrina canónica, porque no siempre se distinguen con claridad de los actos administrativos. Como escribe el propio De la Hera en la obra citada: «Entendemos por normas singulares aquellas que no captan a sus destinatarios por un supuesto de hecho, y que por tanto no exigen para su aplicación el paso de lo abstracto a lo concreto» (Ibidem, p. 210). Entre ellas se incluye el privilegio (ley privada concedida con intención benévola), la dispensa (relajación de la ley meramente eclesiástica en un caso particular), que se concede mediante rescripto y, en cierto modo, el precepto singular. 


\section{P. ¿Qué trayectoria seguiste en los siguientes años?}

R. En la cátedra de la Universidad de Murcia estuve dos años. Allí estaba Mariano López Alarcón, que entonces era Profesor Adjunto, y que también pertenecía a la carrera judicial, siendo en aquel momento Juez-Decano. Se trataba de un colaborador de primera línea, que mereció sin duda la cátedra que pronto obtuvo en una siguiente oposición. Concurrí después al concurso de acceso a la cátedra de Sevilla, vacante por haber alcanzado la jubilación mi maestro Giménez Fernández. En Sevilla estuve cuatro años, desde 1967 hasta 1971, durante los que se planteó la revisión del Concordato, a cuyo efecto se designó en el Ministerio de Justicia una Comisión, formada por Ramón Lamas y Laureano Pérez Mier, auditores rotales, y Antonio Mostaza, Ángel López Amo y Amadeo de Fuenmayor, catedráticos de Universidad; yo fui designado secretario. Me trasladaba por ello todos los viernes en el tren de la noche a Madrid, donde pasaba el sábado completo, regresando por la noche a Sevilla. Los sábados eran los días destinados al trabajo conjunto de la Comisión, que se prolongó durante todo un año. Los documentos que redactamos pasaron al Ministerio de Asuntos Exteriores y con el tiempo se procedió a sustituir el Concordato por el conjunto de Acuerdos, actualmente vigentes.

P. ¿Y cómo volviste a la Universidad Complutense de Madrid?

R. Estando en Sevilla se creó en Madrid una cátedra de Historia de la Iglesia en América e Instituciones Canónicas Indianas. Se la declaró accesible desde las cátedras de Derecho Canónico, mediante concurso de traslado. Concurrí al mismo y en 1971 obtuve dicha cátedra. Esta vez el tribunal lo presidía Alfonso García-Gallo, y lo integraban dos catedráticos de Historia de América de la Universidad de Sevilla, José Antonio Calderón Quijano y Antonio Muro Orejón, un catedrático de Derecho Canónico de la Complutense, Isidoro Martín Martínez, en representación de esta disciplina, y Tomás Martín Martínez, catedrático de Paleografía y Diplomática, en representación de la Facultad de Filosofía y Letras a la que se destinaba el concurso. Nadie se sorprendió por aquella decisión mía. Era obvio que me había dedicado desde mis inicios a la Historia de la Iglesia en América y que bajo la dirección de García-Gallo, y previamente de Giménez Fernández, había trabajado de modo constante en ese campo, por lo que el regreso al mismo no suponía otra cosa que un paso normal en el desarrollo de mi vida universitaria y científica.

P. Por cierto, bemos hablado de tu doctorado en Derecho canónico y en Filosofía y Letras, rama de Historia, pero también eres doctor en Derecho...

R. Mientras preparaba en Pamplona mi oposición a cátedra, en el comienzo del año 1966, Pedro Lombardía me hizo notar que, legalmente, me era posi- 
ble acceder a una cátedra de Derecho con un doctorado en Filosofía y Letras, pero que no dejaría de resultar extraño que desempeñase una cátedra en Derecho quien no fuese doctor en esa Facultad. Así que me propuso que accediese a dicho doctorado. Como poseía todos los requisitos legales para ello, y tan sólo me faltaba presentar una tesis, cerré en poco tiempo un trabajo nuevo y original que tenía prácticamente concluido y preparado para una posterior publicación, solicité el doctorado, presenté la tesis y cubrí aquel lógico requisito que Pedro Lombardía sensatamente juzgó conveniente llenar. Fue mi tercer doctorado, y también está publicada esta tercera tesis, un nuevo libro sobre la cohabitación conyugal ${ }^{12}$. Señalaré una vez más la composición del tribunal, porque los nombres de sus integrantes van marcando la presencia de los grandes maestros de la época en la promoción de las nuevas generaciones. Mi tesis en Derecho, pues, la juzgaron Francisco Sancho Rebullida, catedrático de Derecho Civil, como presidente del tribunal; José Orlandis, de Historia del Derecho, Jorge Carreras, de Derecho Procesal, y Pedro Lombardía, como vocales; y Javier Hervada como secretario. Y recuerdo, porque me resultó muy estimulante, que una vez defendida la tesis, me llamó Pedro Lombardía para decirme: «Si opositas a cátedra tal como has defendido la tesis, ya verás que la vas a obtener». Que así te hable tu maestro la verdad es que anima bastante.

P. Retomando la secuencia cronológica, ¿cómo fue tu segunda etapa en la Universidad Complutense, ya como catedrático?, ¿tu idea era permanecer siempre en el ámbito universitario o tenías otras aspiraciones?

R. Como queda dicho, en 1971 estaba de vuelta en Madrid, con intención de permanecer en la Universidad hasta mi jubilación. Nunca tuve intención de ejercer como abogado. De hecho, le recordé a mi padre que con Filosofía y Letras se podía vivir: «Ya soy catedrático de Derecho canónico -le dije-, y paso ahora a una cátedra de Historia de la Iglesia en América. Siempre quise ser catedrático de Filosofía y Letras». Y me contestó: «Sí, ya veo que con Filosofía y Letras también puedes ganarte la vida». Y, en efecto, desde 1971 hasta el año 2002, en que me jubilé, he trabajado como catedrático en la Facultad de Filosofía y Letras -luego Geografía e Historia- en la Universidad Complutense de Madrid.

Conservo muy buenos recuerdos y experiencias de esta treintena de años. A los cuatro años de regresar, en 1975, me eligieron Decano de la Facultad. Fue una etapa bastante movida políticamente. Las primeras conferencias que pronun-

12 Alberto DE LA HERA, Relevancia jurídico-canónica de la cohabitación conyugal, Pamplona, 1966. Vid. también ID., La cohabitación en el matrimonio, en Ius Canonicum, 5 (1965), pp. 499-544. 
ciaron después del exilio Enrique Tierno Galván y Claudio Sánchez Albornoz, las dieron en la Facultad, invitados por mí. He de admitir que me correspondió desempeñar un protagonismo democrático, en una etapa en la que no faltaron las algaradas, los movimientos estudiantiles, los enfrentamientos... Mediar en todo ello desde el Decanato fue una tarea no fácil pero resultó bien parada. Y en ese cargo estuve hasta 1977, cuando el nuevo Rector, Ángel Vian Ortuño (19761981), me nombró Vicerrector de Ordenación Académica, es decir, responsable del profesorado. En 1979 nombraron Ministro de Cultura a Manuel Clavero, catedrático de Derecho Administrativo de la Universidad de Sevilla, donde habíamos sido muy buenos amigos. Conocía perfectamente mi afición por el teatro y me nombró Director General de Teatro y Espectáculos; bueno, en realidad, como ya he explicado, materialmente a quien se nombró en primera instancia fue a mi padre.

P. ¿Y de dónde te viene esa querencia por el Teatro?

R. Vamos a ver, yo he tenido toda mi vida una profesión que es la enseñanza, una afición que es el teatro y un capricho que es el dominó. Siendo catedrático en Murcia, organicé un grupo universitario de teatro, que fue campeón de España de teatro universitario y la representó en un certamen internacional de teatro en Estambul, donde estuve un mes dirigiendo el grupo. En el tiempo que estuve en Murcia, durante los veranos me fui un mes por los pueblos de España, dando representaciones con el grupo teatral universitario murciano. Alquilábamos un autobús, donde viajábamos nosotros junto con los decorados. Previamente, nos poníamos de acuerdo con los Gobernadores civiles de distintas provincias y les pedíamos que nos recomendaran a qué pueblos podíamos acudir: siete u ocho pueblos pequeños por provincia, donde no hubiese habido nunca teatro. Contactábamos con los alcaldes respectivos que, cuando llegábamos, nos tenían preparado alojamiento en diversas casas de los lugareños: lo mismo te tocaba en una casa la habitación principal, que en otra la de invitados y en otra el pajar: pura suerte. Actuábamos en las plazas públicas a la caída del día, cuando los campesinos regresaban de sus trabajos, y solíamos tener muy buenas acogidas. Aquello me proporcionó un cierto prestigio en ese mundillo y, de hecho, siendo ya catedrático en Madrid, me nombraron miembro del Jurado Nacional de Teatro, donde conocí y me hice amigo de José María Rodero, de Alfredo Marsillach, de Concha Velasco, de Fernando Fernán Gómez, de Irene Gutiérrez Caba, de Gustavo Pérez Puig, de Marisol... Así que, cuando me nombraron Director General de Teatro, nadie se sorprendió en ese mundo. Estuve en el cargo un año, entre 1979 y 1980, el tiempo que estuvo Clavero en el Ministerio de Cultura. En cuanto cesé me llamó el Rector Vian para que volviera 
como Vicerrector, y así lo hice, con lo cual estuve en el cargo y a su lado siete de los ocho años que duró su mandato.

\section{P. Pero también fuiste Secretario General de la Complutense...}

R. Sí, pero eso fue cuatro años más tarde, cuando fue elegido Rector el profesor Amador Schüller (1983-1987). Inicialmente también me nombró Vicerrector de Ordenación Académica pero, al cabo de un tiempo, me propuso ser Secretario General, puesto que necesitaba una reordenación administrativa de la Universidad que consideró que yo podía llevar a cabo. Ya ves, aquí también se tuvo en cuenta mi presunta capacidad organizativa. Y allí seguí hasta que Schüller concluyó su rectorado, y regresé entonces a mi cátedra de Historia de América -aunque nunca había dejado de atenderla, pues todo se podía compatibilizarhasta una nueva situación que apareció en 1996.

En todo ese tiempo participé en Congresos internacionales de Historia del Derecho indiano y viajé mucho dando conferencias sobre esa materia. GarcíaGallo era el presidente del Instituto Internacional de Historia del Derecho indiano, cuya sede principal está en Buenos Aires; siempre que él acudía a los Congresos internacionales, yo le acompañaba. Mi trato con él fue ininterrumpido. Desde que volví a Madrid como catedrático, nos veíamos diariamente, y con el tiempo llegué a acompañarle hasta su sepultura. He sido discípulo de García-Gallo tanto como de Pedro Lombardía. Mis dos maestros fueron Pedro Lombardía en Derecho Canónico y Alfonso García-Gallo en Historia de la Iglesia y del Derecho, y de las Relaciones Iglesia-Estado; sin olvidar que el profesor Giménez Fernández fue quien encendió la luz y despertó mi vocación universitaria.

En Madrid acabé trabajando con los dos, pues Pedro Lombardía accedió a una cátedra de Derecho Eclesiástico del Estado en la Complutense en 1985 y, aunque sólo estuvo un curso curso (1985-1986), pues poco después enfermó y falleció (28-IV-1986), le dio tiempo para fundar el Anuario de Derecho Eclesiástico del Estado. La venida de Pedro a Madrid estuvo motivada por su intención de impulsar desde allí esa nueva materia ${ }^{13}$, que había venido a susti-

13 A diferencia de lo que sucede en Italia, donde recibe el nombre de Derecho Eclesiástico, sin más, en España es habitual añadir las palabras del Estado, para evitar que prima facie se confunda con el Derecho Canónico. En cualquier caso, puede definirse como «aquel sector [o rama] del ordenamiento jurídico del Estado que regula el fenómeno religioso -la dimensión religiosa de la vida del hombre- en cuanto se manifiesta como factor social específico en el ámbito civil (cfr. Pedro LOMBardía (†) y Juan FornÉs, El Derecho Eclesiástico, en Javier FERRER OrTIZ (coord.), Derecho Eclesiástico del Estado Español, Pamplona, ${ }^{6} 2007$, reimpresión ${ }^{3} 2012$, p. 22). Se trata del primer manual de la disciplina publicado en España, bajo el impulso de Pedro Lombardía, que en sus primeras ediciones, de 1980 y 1983, fue quien lo coordinó. En cuanto al contenido del Derecho 
tuir como materia troncal (obligatoria en todas las Facultades de Derecho de España) al Derecho Canónico que, entonces, en el mejor de los casos permaneció como materia obligatoria u optativa en algunas pocas Facultades. Era un absoluto absurdo, separándose del camino seguido por ambas materias en otros países, singularmente Italia; pero así sucedió por evidentes motivos no científicos sino políticos. En este contexto se entiende que, cuando Pedro se trasladó a Madrid, siendo yo Secretario General de la Complutense, le dije que estaba en condiciones de favorecer su tratamiento de la nueva asignatura proporcionándole ayuda para crear un Instituto, una Revista, o alguna otra actividad similar. Fue entonces cuando me manifestó su deseo de fundar un Anuario de Derecho Eclesiástico del Estado. Y con el apoyo de la Complutense, de la Editorial Edersa y de otras instituciones, el Anuario apareció por vez primera en 1985, un año antes del fallecimiento de su fundador, que ya no llegó a poder ver el segundo volumen. Me correspondió sucederle en la Dirección, que he seguido desempeñando hasta hoy, puesto que había sido con él subdirector en el tomo primero de la nueva revista.

P. ¿Y qué me cuentas de tus discípulos? Háblame de ellos.

R. En Derecho Canónico el primero fue Iván Ibán y en Historia de la Iglesia en América Rosa María Martínez de Codes. Esos son mis dos discípulos por antonomasia, a los que he formado a fondo, desde la carrera, la tesis doctoral, la ayudantía, la adjuntía y la cátedra. Al haberme mantenido en los años pasados más cerca de la Historia americana que del Derecho Canónico, sigo manteniendo una relación mucho más estrecha con Rosa María que con Iván, pero ambos son hoy catedráticos de la Complutense y de ambos estoy orgulloso.

P. ¿Y de tu amplia producción científica, qué trabajos destacarías?

R. Vamos a ver, a mí nunca me ha gustado escribir. Lo que me ha gustado siempre es dar clase, la enseñanza, no la escritura. Si de mí hubiera dependido, hubiera sido uno de esos catedráticos que nunca publican y que se pasan la vida dando clase, que los hay. Pero Pedro Lombardía me dijo que había que escribir, que no tendría nombre ni sería nadie si no publicaba. De hecho, como ya he dicho, publiqué mis tres tesis y luego, con la Memoria de oposición a la cátedra,

Eclesiástico de Estado, el Real Decreto 1424/1990, de 26 de octubre, de Directrices directrices generales propias de los planes de estudios conducentes a la obtención del Título oficial de Licenciado en Derecho, especificó: «La tutela de la libertad religiosa en el Derecho español y comparado. Reflejos jurídicos (enseñanza, matrimonio, asistencia religiosa, objeción de conciencia). Régimen jurídico de las relaciones entre el Estado y las Iglesias y confesiones religiosas» (BOE, de 20 de noviembre de 1990, p. 34356). 
publiqué un libro titulado Introducción a la Ciencia del Derecho Canónico ${ }^{14}$. Es verdad que tengo muchas otras publicaciones, pero no porque disfrute haciéndolo. También he escrito muchas recensiones, pero porque tengo una idea clara: al que inicia la investigación de un tema y busca la bibliografía adecuada para su tratamiento, el contacto con las secciones bibliográficas de las revistas le permite en poco tiempo ver cuáles son los libros que aportan algo a su tema y qué puede esperar de ellos. Por eso siempre he sido muy amigo de las recensiones, pensando que presto un servicio, aunque no me gusta escribirlas.

¿Qué cuáles son mis líneas de investigación fundamentales? El Regalismo borbónico y sus mil adherentes en torno a él; la Introducción al Derecho Canónico, con sus mil adherentes en torno a él; el Derecho matrimonial canónico y civil; y las Relaciones Iglesia-Estado, particularmente en América. Es verdad que he publicado muchos otros trabajos, sobre otras materias, pero siempre como respuesta a invitaciones concretas a escribir sobre ellas. En muchas ocasiones Pedro Lombardía y otros colegas españoles y de diversos países, y directores de variadas revistas, y organizadores de diversos simposios, se han dirigido a mí para proponerme que estudiase un tema, o llevase una ponencia a un congreso, o colaborase en un volumen colectivo. Y muchas veces he aceptado.

Un caso excepcional fue el artículo sobre el Sínodo romano ${ }^{15}$, que ahora te explico. Cuando iba a salir el primer número de Ius Canonicum, Pedro Lombardía y Javier Hervada se preguntaron si yo, historiador que entonces estaba explicando Historia del Derecho Canónico, podría escribir sobre un tema de Derecho Canónico actual. ¿Puede el historiador ocuparse también del Derecho positivo vigente? Y así me propusieron el tema del entonces recién celebrado Sínodo romano, que había convocado Juan XXIII; y no debí hacerlo mal, puesto que aceptaron mi escrito y se publicó en la nueva revista, prólogo de tantos otros trabajos de Derecho vigente que he debido preparar a lo largo de los años. Pero mis grandes temas son los que he dicho, muy en especial la Historia de las Relaciones IglesiaEstado en América y el concepto general del Derecho Canónico.

P. ¿Entonces, eso que se dice en la Universidad de que es muy importante que los profesores se dediquen a la docencia y a la investigación, y en menor medida a la gestión...?

R. A mí lo que me gusta es la docencia y, en segundo lugar, la gestión; pero la docencia, en concreto, no es realmente posible sin una seria base de investi-

14 Alberto DE LA HERA, Introducción a la Ciencia del Derecho Canónico, Madrid, 1967.

15 ID., Introducción al estudio del Sínodo Romano, en Ius Canonicum, 1 (1961), pp. 233-261. 
gación y estudio. Escribir me agrada mucho menos, pero los miles de páginas que han salido de mis manos ahí quedan. Gracias a Dios he tenido siempre buena salud, y la sigo teniendo, bien sé que mientras Dios quiera. Nunca me he sentido cansado y he estado muy pocas veces enfermo; he dormido poco, porque no me ha hecho falta más; y no he sabido hacer otra cosa que trabajar. No he sido hombre de deporte, ni de excursiones, ni de museos, ni de música, ni de turismo... Acudiendo a un gran número de congresos internacionales, nunca los he aprovechado para el turismo. Sólo una vez, al terminar un Congreso en Lima, mi mujer me dio la sorpresa de llegar, y me llevó a visitar el Cuzco y Machu Picchu que, la verdad, son lugares que me sorprendieron muy gratamente y me gustaron muchísimo. También, durante mi etapa como Director General de Asuntos Religiosos, hube de visitar muchos países, pero siempre centrado en el plan de trabajo que me llevaba allí. Así que he podido hacer turismo, pero no lo he hecho.

P. Ya que acabas de mencionarlo, podemos hablar abora de tu paso por la Dirección General de Asuntos Religiosos, durante los años 1996-2004.

R. De acuerdo. En el año 1996 ya había dejado la Secretaría General de la Complutense y había regresado a prestarle una atención exclusiva a mi cátedra, asumiendo también la dirección del Departamento de Historia de América de mi Facultad. Y en ello estaba cuando ganó las elecciones en 1996 José María Aznar, que designó como Ministra de Justicia a Margarita Mariscal de Gante, que procedía de la carrera judicial y no había tenido hasta entonces actividad política. Obligada a ello por el cargo, hubo de buscar personas aptas para las diversas Direcciones Generales, y le fue recomendado mi nombre para los Asuntos Religiosos. Nos entrevistamos, nos pusimos fácilmente de acuerdo y asumí en ese año la mencionada Dirección General.

Formé un equipo con Rosa María Martínez de Codes, mi discípula más cercana, y con Joaquín Mantecón Sancho, Profesor Titular entonces de Derecho Eclesiástico del Estado en la Universidad de Jaén, al que había conocido poco antes durante una visita a dicha Universidad, en la que saqué la mejor impresión de él, de sus conocimientos y de su capacidad de trabajo. Como necesitaba dos Subdirectores Generales, uno con mayor proyección internacional y otro para tareas internas de organización, llamé a mi lado a los dos. Así fue como Joaquín Mantecón se encargó de llevar el trabajo interno diario de la Dirección General, del que me descargó en muy buena medida, permitiéndome afrontar la tarea de internacionalizar los temas de la presencia de las Confesiones religiosas en España, de modo que pronto habíamos atraído la atención de gran cantidad de especialistas y líderes religiosos de múltiples países. Se celebraron entonces en 
España varios Congresos internacionales de gran éxito ${ }^{16}$, y nuestra política en el campo de las relaciones del Estado con las Confesiones religiosas fue muy pronto objeto de una atención universal.

A Margarita Mariscal de Gante le sucedió, en el año 2000, Ángel Acebes al frente del Ministerio de Justicia. Continué en la Dirección General -me consta que el Presidente Aznar deseaba que fuese así- pero entonces otros temas hubieron de atraer la atención más directa del Ministerio, si bien lo ya alcanzado se mantuvo. Además, fue entonces cuando Rosa María obtuvo su cátedra y hubo de dejar el Ministerio. Llamé entonces a la Subdirección a Joaquín Martínez Gijón, un excelente técnico de la Administración civil, y con ello la actividad interna continuó a un alto nivel de eficacia; pero las relaciones internacionales hubieron de mermarse notablemente.

La sustituyó a Acebes en el Ministerio, en el año 2002, José María Michavila, con el que yo tenía una cierta amistad. Regresó entonces a la Subdirección Joaquín Mantecón, que la había tenido que dejar durante un tiempo por exigencias de su carrera universitaria, y con él y Martínez Gijón nos desenvolvimos en las actividades que entonces resultaban posibles manteniendo un buen nivel.

16 Entre 1985 y 2000 se celebraron en España nueve Congresos Internacionales de Derecho Eclesiástico del Estado: Jerez de la Frontera (1985), Segovia (1986), Oviedo (1987), Valladolid (1988), Pamplona (1990), Valencia (1992), Barcelona (1994), Granada (1997) y San Sebastián (2000). Alberto de la Hera fue uno de sus promotores y presidió el de Segovia. Cuando accedió a la Dirección General de Asuntos Religiosos siguió prestándoles su apoyo y entusiasmo.

Además promovió otros encuentros internacionales, con grupos más reducidos, pero igualmente interesantes, que se materializaron en diversas publicaciones del Ministerio de Justicia: Alberto DE LA HERA y Rosa María MARTÍNEZ DE CODES (coords.), Encuentro de las tres Confesiones religiosas. Cristianismo, Judaísmo, Islam, Madrid, 1999; Alberto DE LA HERA (presentación), La libertad religiosa a los veinte años de su Ley orgánica, Madrid, 1999; Alberto DE LA HERA y Rosa María MARTÍNEZ DE CODES (coords.), Encuentro sobre dignidad humana y libertad religiosa, Madrid, 2000; ID., Foro Iberoamericano sobre libertad religiosa, Madrid, 2001; ID., La Libertad Religiosa en la Educación Escolar. Conferencia Internacional Consultiva de Naciones Unidas sobre la Educación Escolar en relación con la Libertad de Religión y de Convicciones, la Tolerancia y la no Discriminación, Madrid 2002; y Joaquín MANTECÓN (coord.), Los Acuerdos con las Confesiones Minoritarias. Diez Años de Vigencia, Madrid 2003.

También impulsó directamente otras publicaciones en el Ministerio de Justicia, sobre cuestiones relevantes de Derecho Eclesiástico del Estado: Margarita MARISCAL DE GANTE (prólogo), Guía de Entidades Religiosas de España (Iglesias, Confesiones y Comunidades minoritarias), Madrid 1998; Alberto DE la Hera y Rosa María MARTíneZ DE CODES (eds.), Spanish Legislation on Religious Affairs, Madrid 1998; Alberto DE LA Hera y Rosa María MARTíNEZ DE CODES (coords.), Proyección nacional e internacional de la libertad religiosa, Madrid 2001; Rosa María MARTÍNEZ DE CODES y Jaime RossELl (coords.), Religious Freedom, Tolernce and Non-Discrimination in Education, Madrid 2001; Alberto DE LA HERA y Daniel IRASTORZA (coords.), La Financiación de la Libertad Religiosa, Madrid 2002; Alberto DE la Hera, Agustín Motilla y Rafael Palomino (coords.), El Ejercicio de la Libertad Religiosa en España: Cuestiones Disputadas, Madrid, 2003; y Joaquín MANTECóN (coord.) Confesiones Minoritarias en España. Guía de Entidades y Vademécum Normativo, Madrid, 2004. 
P. ¿Y en ese tiempo qué biciste en el panorama interno español, cuáles fueron los temas de mayor interés de los que te ocupaste y cómo fueron las relaciones con la Iglesia católica y con las demás confesiones?

R. Me parece que mis mayores logros con las confesiones minoritarias fue que les di un protagonismo que no habían tenido hasta entonces. Y me llevé muy bien con sus principales dirigentes: Mariano Blázquez (FEREDE) ${ }^{17}$, Isaac Querub $(\mathrm{FCJE})^{18}$ y Riay Tatary (CIE) ${ }^{19}$. Trabajaron en firme, pusieron todo su empeño en entenderse entre sí, con la Iglesia católica y con el Estado, y se abrió un periodo que ha dado luego excelentes frutos en orden al desarrollo y consolidación de la libertad religiosa en España.

Con la Conferencia Episcopal Española las relaciones fueron igualmente fluidas, pues me pude entender muy bien con el que entonces era Secretario General de la misma, el actual arzobispo de Sevilla, don Juan José Asenjo, persona muy inteligente y prudente, que organizaba muy bien las cosas y llevaba muy bien los asuntos. Con otros obispos, como el cardenal Rouco, del que había sido compañero de estudios en Múnich, con el actual arzobispo de Pamplona don Francisco Pérez González, con el hoy Presidente de la Conferencia Episcopal Mons. Blázquez, con el obispo de Almería don Adolfo González Montes, por poner algunos ejemplos, hube de tener contactos importantes para atender temas de común interés para la Iglesia y el Estado, y lo cierto es que en todo ellos encontré afán de cooperación y excelente voluntad de entendimiento.

P. ¿Te tocó la famosa sentencia del Tribunal Constitucional sobre el Registro de Entidades Religiosas ${ }^{20}$, dependiente de la Dirección General?

R. Sí, me tocó. Se dictó durante mi estancia en la Dirección General. El Registro se había convertido literalmente en un caos. Se dividía en tres grupos: las entidades religiosas inscritas, las entidades no religiosas y disfrazadas de religiosas también inscritas, y las entidades religiosas que no se habían inscrito. Intenté eli-

17 Federación de Entidades Religiosas Evangélicas de España.

18 Federación de Comunidades Judías de España.

19 Comisión Islámica de España.

20 Cfr. STC 46/2001, de 15 de febrero, por la que se resuelve la inscripción de la Iglesia de la Unificación. Tal y como dispone la Ley orgánica 7/1980, de 5 de julio, de Libertad Religiosa, la inscripción de las Iglesias, Confesiones y Comunidades Religiosas en el registro específico, dependiente del Ministerio de Justicia, es condición necesaria para que gocen de personalidad jurídica en el Derecho español (art. 5); para que tengan plena autonomía y puedan establecer sus propias normas de organización, régimen interno y régimen de su personal (art. 6.1); y para que, en su caso, el Estado estipule con ellas Acuerdos de cooperación, siempre y cuando que adicionalmente hayan obtenido la declaración de notorio arraigo en España (art. 7.1). 
minar del Registro a las segundas, muchas de las cuáles no eran en realidad sino entidades económicas, políticas, incluso contrabandistas, traficantes de armas..., disfrazados en muchos países de entidades religiosas para pasar inadvertidas o para aprovechar determinados beneficios sociales, fiscales o culturales. A tal fin hube de conectar a nivel internacional con embajadas, policía, investigadores, a efectos de comprobar si en sus países de origen o difusión estaban tales agrupaciones legalmente reconocidas, qué actividades tenían, si de verdad eran o no religiosas. También traté que se inscribieran las entidades religiosas que no lo estaban y quisieran inscribirse, dándoles toda clase de facilidades. Entonces llegó la famosa sentencia que prohibía investigar la verdad del carácter religioso de las entidades que afirmaban poseerlo, y vinieron los periodistas a preguntarme: «¿Qué va a a hacer?». «Nada -les dije-. La sentencia recae sobre algo que se hizo durante el Gobierno de Felipe González: la admisión de estas entidades en el Registro, no sobre algo que se haya hecho ahora. Y nuestra misión es simplemente cumplirla». No se creó ningún problema. Pero como establecía que no se pudiese indagar sobre la veracidad de los intereses religiosos de quienes afirmaban poseerlos como una condición básica para poder inscribirse como entidad religiosa, bastó detener todas las indagaciones que se venían realizando. Así que acaté la sentencia, aunque no la comparto. Y, a partir de ese momento, se dejó de prestar atención -una atención que hubiese sido muy conveniente- al carácter real de las entidades inscritas o por inscribir en el Registro de Entidades Religiosas.

P. Siguiendo, con estos temas, ¿consideras que es necesario reformar la Ley orgánica de libertad religiosa de 1980? Lo pregunto porque ba sido y sigue siendo un punto de referencia en Latinoamérica y en Europa.

R. Desde luego, yo no la modificaría. Prefiero no tocarla, para hacerlo tendría que estar muy seguro de que se va a mejorar, y me parece difícil hacerlo. Fijémonos en tres países: Italia, Portugal y España. Estando en el Ministerio de Justicia, convoqué a los Directores Generales de esos dos países para intercambiar experiencias y conocimientos. Concluimos que hay tres maneras de regular los temas religiosos: o se hace una ley tan extensa y detallista que haga innecesarios los acuerdos de cooperación con las confesiones, o se hace una ley genérica que haga necesarios los acuerdos, o no se hace nada, ni acuerdos ni ley, y las confesiones se rigen sin más por el derecho común.

Portugal optó por una Ley de libertad religiosa muy extensa ${ }^{21}$, que hace innecesarios los acuerdos y, salvo el Concordato con la Iglesia católica, no había

21 Cfr. Lei 16/2001, de 22 de junbo, da Liberdade Religiosa. 
acuerdos con las demás confesiones. España optó por una Ley orgánica de libertad religiosa, general y breve, que hace necesario luego resolver con cada religión las cuestiones de detalle mediante acuerdos singulares, si bien después de 1992 no se han firmado otros, y las confesiones que no tienen acuerdos propios están accediendo a derechos y situaciones relacionales a través de muy diversas vías. Italia empezó a firmar acuerdos directamente, sin ley de libertad religiosa, y cuando se habían ya firmado unos pocos se reparó en que, siendo muy diferentes unos de otros, se estaba provocando un cierto caos normativo. Entonces se acordó detener la firma de acuerdos y, no poseyendo tampoco una ley de libertad religiosa, prima el Derecho común para su aplicación a las diversas entidades religiosas.

P. Cambiando de tercio, desde tu experiencia y tu conocimiento ¿qué futuro le ves en la Universidad española al Derecho Canónico y al Derecho Eclesiástico del Estado?

R. El Derecho Canónico como tal prácticamente ha desaparecido de las Facultades de Derecho en España. En algunas se mantiene una asignatura de Derecho Matrimonial Canónico o de Derecho Matrimonial Comparado, con una parte canónica; lo que contrasta con el interés que suscita la materia entre los estudiantes mientras se mantiene. Y, en cuanto al Derecho Eclesiástico del Estado, ha empezado ya a desaparecer en diversas Facultades. Ciertamente, el nombre nunca ha ayudado, pero no se ha encontrado otro mejor. Te doy dos datos. Primero: le llaman Derecho Eclesiástico en Alemania, en Italia, en Francia... y en Latinoamérica, en aquellas Universidades que lo han incorporado recientemente. En todas partes le llaman Eclesiástico. Segundo dato: los temas que tengan algo que ver con la religión, aunque sea desde el punto de vista del Estado, cada vez interesan menos. La asignatura está desapareciendo, y las razones nada tienen que ver con la ciencia: es pura política, tan cobardemente gestionada, cuando no con intenciones claramente contrarias a la menor presencia de la religión en el ámbito público.

P. Pero todos los días los medios de comunicación social publican noticias relacionadas con la libertad religiosa, y a la gente le interesan...

R. Vamos a ver, son hoy muchos los políticos enemigos de todo lo que suene a religión, por definición. Enemigos de todo lo que suene a religión, provenga de donde provenga y sea lo que sea. Y examinemos el hecho: las leyes tienen que responder a la justicia y a la verdad. Pero, ¿quién define los criterios de justicia y de verdad? O provienen de Dios, o del individuo singular, o del conjunto social, o del Estado. Si provienen del Estado estamos ante la dictadura, si de cada individuo singular es el caos, si del conjunto social estaremos ante el relativismo. Así que no queremos ni dictadura, ni el caos; y si admitimos que los principios inspiradores de las leyes provengan del conjunto social, nos encontramos con que 
la justicia y la verdad, el qué sea cada una, que es lo justo y qué es lo verdadero, pasa a depender del partido que en cada caso gane unas elecciones, con lo que una misma cuestión hoy es legítima, cuatro años después es un delito, luego vuelve a cambiar, etc. Por tanto, la verdad y la justicia solo pueden proceder de Dios, sea el de los cristianos, de los musulmanes, de los judíos..., porque en este punto hay pocas diferencias entre las religiones. Pero un amplio sector de la política y la cultura nunca va a reconocer que no se debe ir alterando constantemente el concepto de lo justo y lo verdadero, sin que ello relativice la propia vida del ser humano. Por tanto, todo lo que tenga que ver con la religión significa abrir la puerta a que la ley tiene que inspirarse en la verdad y en la justicia. Importantes sectores políticos sostienen en realidad que lo conceptos de justicia y verdad proceden de la sociedad, del grupo, de la mayoría, pero solamente hasta que consiguen controlar el Estado, y pasan entonces a sostener que no hay otra fuente de la ley que el propio Estado. Y así es tan frecuente que esas presuntas democracias terminen dando paso a dictaduras de las que ya se hace muy difícil salir.

En el otro lado tenemos la cobardía y el complejo de tantos otros sectores de la política que ceden en todo frente a la posibilidad de ser tildados de fascistas o calificativos similares. Así, contentándose con sus éxitos en economía o en comercio, ceden por completo la educación y la cultura, a cuyo través se forma a las juventudes y se desconcierta a los pueblos. En España, el resultado final es que aquello que proclama el artículo 16.3 de la Constitución, según el cual «los poderes públicos tendrán en cuenta las creencias religiosas de la sociedad española...», resulta ser un precepto que ni se cumple ni se tiene en cuenta para nada.

Existiendo pues, como existe, un empeño sectario con voluntad de ir eliminando de modo gradual pero constante la religión de la sociedad, no le auguro un buen futuro a la asignatura de Derecho Eclesiástico del Estado, la cual, curiosamente, no trata de las normas propias de las confesiones, sino de las leyes que el Estado dicta para regular los fenómenos religiosos en su dimensión social.

P. $i M e$ puedes comentar tus cargos al frente de distintas instituciones?

R. Durante mi etapa como Director General de Asuntos Religiosos entré en contacto con la International Religious Liberty Association, con sede en Silver Springs (USA), creada en el siglo XIX por los Adventistas y que posteriormente ha crecido mucho, desbordando todos sus límites iniciales. Está hoy constituida por personas y entidades de los más diversos credos y países, y mantiene una relación de colaboración con las Naciones Unidas. La Association me invitó a varios Congresos, en los que participé como ponente; ingresé como miembro de la misma; y, al cabo del tiempo, fui designado para una de las vicepresidencias, cargo que mantengo en la actualidad. Su misión es defender la libertad religio- 
sa, para lo cual mantiene una relación permanente con todos los Gobiernos del mundo.

También soy consultor del Consejo Pontificio para la Interpretación de los Textos Legislativos; e igualmente pertenezco al European Consortium for Church and State Research, con sede en Milán, fundado por Pedro Lombardía, Pietro Agostino d'Avack ${ }^{22}$ y Pietro Gismondi ${ }^{23}$, y del que fui Presidente. También lo he sido del Instituto Internacional de Historia del Derecho Indiano, fundado por Alfonso García-Gallo junto con un profesor chileno, Alamiro de Ávila, y un argentino, Ricardo Zorraquín. El Instituto empezó a celebrar Congresos internacionales bajo la dirección conjunta de los tres fundadores, que desempeñaban el cargo de Presidentes. Cuando hubieron fallecido los tres, se designó como único Presidente a un profesor argentino, José María Mariluz Urquijo y, al concluir su mandato, se decidió que correspondía nombrar presidente a un europeo y me designaron a mí. Luego también he sido Presidente de la Asociación Española de Americanistas, con sede en Sevilla, y Vicepresidente de la Consociatio Internationalis Iuris Canonici Promovendo, con sede en Roma. Muchas actividades y muy variadas; unas de mayor empeño que otras; todas comunes en el esfuerzo para que España esté presente en los campos científicos en los que mis colegas y yo mismo nos movemos.

P. Antes de terminar, quería comentarte que be seguido tu trayectoria, también durante estos últimos años, y estás muy activo. No parece que estés jubilado...

R. La verdad es que ahora no doy clases, porque jurídicamente no puedo. Pero he seguido dando conferencias, de modo ocasional o con cierta regularidad, por ejemplo en el Instituto de Estudios Bursátiles o en el Club Cultural Zayas. Sin embargo, ha llegado un momento, entrados los ochenta años, en que he considerado que no debía seguir. Así que últimamente, amén de algunos congresos y conferencias, que de vez en cuando surgen, me he centrado en la dirección del Anuario de Derecho Eclesiástico del Estado; pero en el año 2019 la revista publica su volumen número 35: ya es suficiente para un Director, así que lo dejaré desde el año 2020 en manos más jóvenes y más capaces que las mías.

22 Cfr. Francisca PÉREZ-MADRID, «Pietro Agostino d'Avack (1905-1982)», en Rafael DomiNGO (ed.), Furistas Universales, vol. IV, cit., pp. 460-463.

23 Cfr. Lucia Graziano, «Gismondi, Pietro», en Javier Otaduy y Antonio Viana Joaquín SedaNO (dirs. y coords.), Diccionario General de Derecho Canónico, vol. IV, cit., pp. 196-199. 
Al dar por terminada la entrevista nos admiramos de lo rápido que ha pasado el tiempo. Han sido cerca de tres horas sin más interrupciones que las necesarias para cambiar varias veces la cinta de la cassette y comprobar que el móvil también seguía grabando, por aquello de que más vale prevenir que lamentar, y quería asegurarme de no perderme ni una de las palabras de Alberto de la Hera. Una vez más he confirmado sus excepcionales cualidades: su inteligencia y clarividencia para afrontar las cuestiones; su prodigiosa memoria, proporcionarme sin parpadear toda clase de nombres y datos; su capacidad de palabra y su elegancia en el decir; y, como siempre, su ingenio y su simpatía, arrolladoras.

Al terminar, recogí los bártulos de la grabación y mis notas previas, y nos fuimos a comer, donde seguimos hablando de otras cuestiones. Y, después de una breve sobremesa, pues Alberto tenía un asunto que atender, nos despedimos, quedando emplazados a volver a vernos pronto. 